\title{
Missed positional gluteal compartment syndrome in an obese patient after foot surgery: a case report
}

\author{
Rami Khalifa ${ }^{1}$, Madison R. Craft' ${ }^{2}$ Aaron J. Wey ${ }^{1}$, Ahmed M. Thabet ${ }^{1}$ and Amr Abdelgawad ${ }^{3 *}$ (D
}

\begin{abstract}
Background: Gluteal compartment syndrome is an uncommon condition and can be difficult to diagnose. It has been diagnosed after trauma, vascular injury, infection, surgical positioning, and prolonged immobilization from drug or alcohol intoxication. The diagnosis is based on clinical findings and, in most cases, recognizing these symptoms and making a diagnosis early is critical to a complete recovery.

Case presentation: A 53-year-old male who underwent left foot surgery had severe pain to his contralateral hip and posterior gluteal compartment radiating to the right lower extremity immediately postoperative. He was positioned supine with a "bump" placed under his right hip to externally rotate his operative leg during the surgery. Due to the patient's complex past medical history, a presumptive diagnosis of a herniated disc and/or compression of the sciatic nerve was made as a cause for the patient's pain. This resulted in a misdiagnosis period of $36 \mathrm{~h}$ until the patient was diagnosed with unilateral gluteal compartment syndrome. Performing a fasciotomy was decided against due to the increased risk of complications. The patient was treated with administration of IV fluids and closely monitored. On post-op day 6 , the patient was discharged. At three months post-op, the patient was walking without a limp and he had no changes in his peripheral neurologic examination compared to his preoperative baseline.

Conclusion: Gluteal compartment syndrome is a surgical emergency that must be considered postoperatively especially in obese patients with prolonged operation times who experience acute buttock pain. The use of positional bars or "bumps" in the gluteal area should be used with caution and raise awareness of this complication after orthopedic surgeries.
\end{abstract}

Keywords: Gluteal compartment syndrome, Compartment syndrome, Buttock pain, Post-operative complication

\section{Background}

Compartment syndrome in the gluteal area is a rare and often unrecognized syndrome. Trauma, vascular injury, infection, surgical positioning, and prolonged immobilization from drug or alcohol intoxication are the most common causes of gluteal compartment syndrome [1-4]. Early

\footnotetext{
*Correspondence: amratef@doctor.com

${ }^{3}$ Department of Orthopedic Surgery, Maimonides Medical Center,

Maimonides Bone and Joint Center, 6010 Bay Parkway, Brooklyn, NY 11204, USA

Full list of author information is available at the end of the article
}

recognition and treatment can help to prevent long term complications such as residual sciatic nerve problems or renal failure from rhabdomyolysis $[5,6]$.

A systemic review of gluteal compartment syndrome found that $50 \%$ of the gluteal compartment syndrome cases were due to prolonged immobilization after alcohol or other drugs intoxication or after long surgical interventions such as total hip or knee arthroplasty or procedures with complications that prolong OR time [7]. The lithotomy and lateral decubitus positions are commonly used for orthopedic

\section{BMC}

(c) The Author(s). 2020 Open Access This article is licensed under a Creative Commons Attribution 4.0 International License, which permits use, sharing, adaptation, distribution and reproduction in any medium or format, as long as you give appropriate credit to the original author(s) and the source, provide a link to the Creative Commons licence, and indicate if changes were made. The images or other third party material in this article are included in the article's Creative Commons licence, unless indicated otherwise in a credit line to the material. If material is not included in the article's Creative Commons licence and your intended use is not permitted by statutory regulation or exceeds the permitted use, you will need to obtain permission directly from the copyright holder. To view a copy of this licence, visit http://creativecommons.org/licenses/by/4.0/ The Creative Commons Public Domain Dedication waiver (http://creativecommons.org/publicdomain/zero/1.0/) applies to the data made available in this article, unless otherwise stated in a credit line to the data. 
procedures and have been associated with gluteal compartment syndrome [8,9]. Risk factors such as obesity in addition to extended operative time and patient positioning should warrant suspicion of gluteal compartment syndrome when symptoms arise. This article will describe a case of missed gluteal compartment syndrome that followed contralateral foot surgery. The report includes a literature review for positional gluteal compartment syndrome cases following orthopedic surgeries. We only indicated cases that occurred following orthopedic surgeries not performed in the pelvis/hip area so that the postoperative gluteal compartment syndrome is due to patient "positioning" and not due to "local trauma by the surgery".

\section{Case presentation}

\section{Pre-operative history}

A 53-year-old male with diabetes mellitus and documented peripheral neuropathy presented with left foot pain and deformity. He had a previous Lisfranc injury treated with open reduction and internal fixation three years before presentation. The fixation construct failed and the patient developed Charcot arthropathy of the midfoot (Fig. 1). He also presented with stage III posterior tibial tendon insufficiency with a rigid hindfoot valgus deformity and forefoot abduction. The patient was indicated for hardware removal, medial column arthrodesis, and subtalar arthrodesis to correct the flatfoot deformity and a triple hemisection Achilles tenotomy for Equinus deformity. Past surgical history included lumbar spine decompression and fusion a few years prior. The patient had a weight of $149 \mathrm{~kg}$ and a height of $188 \mathrm{~cm}$ resulting in a BMI of 42 .

\section{Operative technique}

In the OR, the patient was positioned supine on a regular operating table with a "bump" made of rolled up two sheets was placed under his right hip to externally rotate his operative leg. A left thigh tourniquet was placed and inflated to $350 \mathrm{mmHg}$ for $120 \mathrm{~min}$. No epidural or regional block was used. The duration of surgery was $3 \mathrm{~h}$ and $53 \mathrm{~min}$. The procedure was performed in the following sequences 1) Complex hard ware removal (broken implant), 2) Precutaneous Achilles tendon lengthening, 3) Fusion of the 1st metatarsal with the medial cuneiform, 4) Fusion of the medial cuneiform with navicular bone, 5) Fusion of the navicular with the talus, 6) Fusion of the subtalar joint 96(Fig. 2). The procedure went uneventful. The patient was extubated and tolerated the procedure during surgery very well.

\section{Postoperative day (POD) 0}

In the immediate postoperative period, the patient complained of $10 / 10$ pain to the right (contralateral) hip and posterior gluteal compartment radiating to the right lower extremity. The patient was more comfortable with the bed at 45 compared to lying flat. An emergent CT scan was obtained to rule out a fracture of the femoral neck or proximal femur and it was negative and did not show any other abnormality around the pelvis area. Due to his prior history of lumbar spine surgery, degenerative changes in the lower lumbar spine with marked narrowing of disc space, and sclerosis of endplates and osteophytes were seen on CT, a presumptive diagnosis of a herniated disc and/or compression of the sciatic nerve was made. An urgent MRI was also ordered that night; however, the patient was unable to lay supine due to pain and the only way to obtain the MRI was under anesthesia. Due to his recent prolonged surgery, a

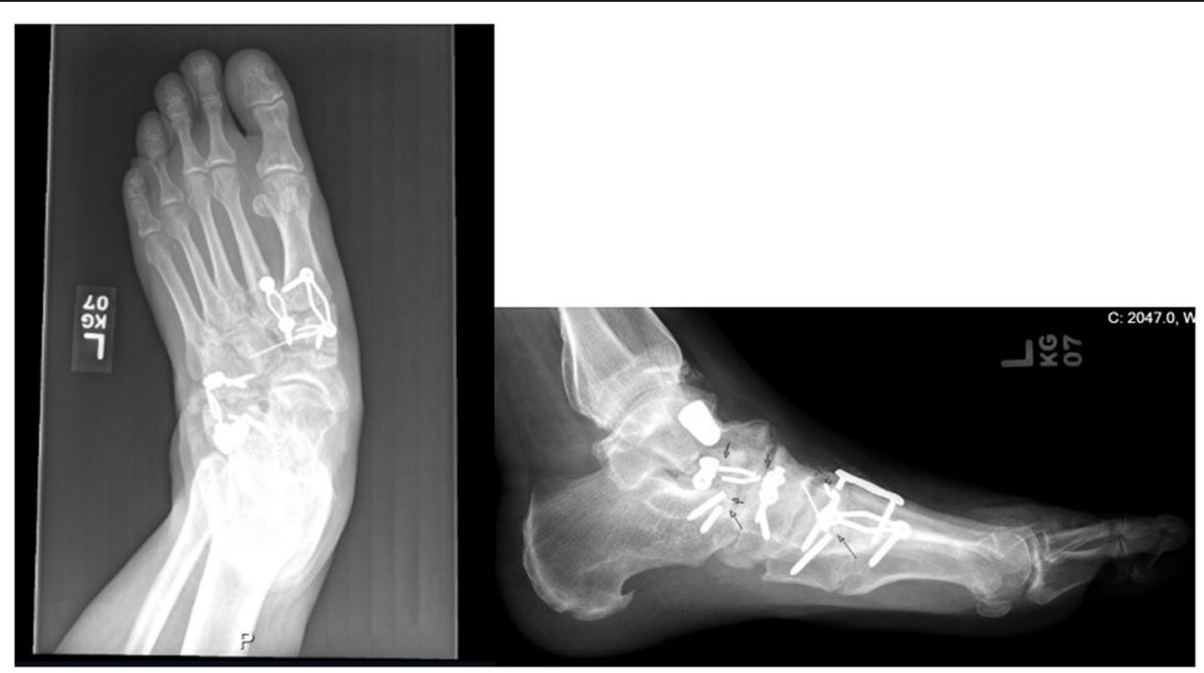

Fig. 1 preoperative Radiographs showing failure of the fixation construct and the patient developed Charcot arthropathy of the midfoot 


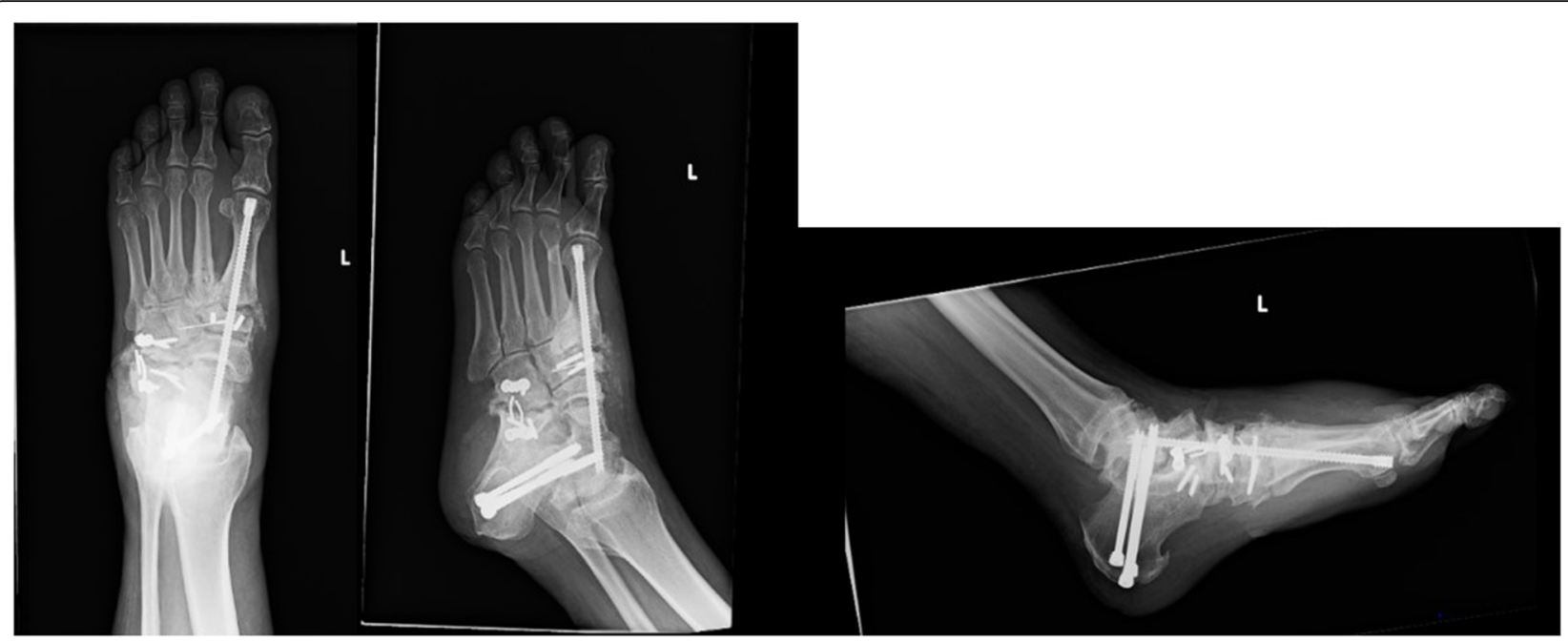

Fig. 2 postoperative radiographs showing fusion of left foot medial column joints and the subtalar joint

decision was reached not to anesthetize the patient a second time for the MRI. The provisional diagnosis of radicular pain and sciatica was the prevailing diagnosis at that time. Please note that the diagnosis of the gluteal compartment syndrome was missed on the day of surgery. The patient experienced uncontrolled pain the night after surgery that did not respond to narcotic pain medication. He stated that the pain in his right lower back and buttocks was more severe than the pain in his left ankle from recent surgery.

\section{POD 1}

On POD 1, the patient continued to complain of radicular pain in the right L5, S1, and sciatic nerve distribution. On physical exam, he had grade 5/5 motor power strength with ankle dorsiflexion, plantar flexion, Extensor Hallucis longus, Flexor Hallucis Longus, knee extension, and knee flexion. The sensation was normal in the L1 to S1 nerve distribution. Dorsalis pedis and posterior tibialis pulses were palpable and symmetric in the left foot. The palpation of the right gluteal compartment was tense. The patient was also much more comfortable laying at $45^{\circ}$ than supine in the bed. He was sent for an MRI of the lumbar spine and right hip. The MRI did not show a lumbar disc herniation but did reveal increased signal in the gluteal compartment (gluteus maximus, medius, and minimus) on the right side (Fig. 3).

\section{POD 2-3}

Systemic blood work obtained on POD 2 included an elevated creatine kinase at 49,688 and a BUN/Cr at 44/1.5. The patient was treated with IV fluids and diagnosed with right gluteal compartment syndrome. Due to the prolonged misdiagnosis in the first $36 \mathrm{~h}$ post-op, the decision was made not to decompress the gluteal compartment to avoid operating on possibly necrosed muscle which would increase the risk for massive infection or significant fibrosis.

\section{POD 4-6}

The patient was observed and treated without surgical decompression. His pain decreased gradually on each post-op day moving forward. Creatine kinase trended down to 12,064 on POD 5, and to 6702 on POD 6. His BUN/Cr improved to $25 / 1.0$ on POD 6 . After walking with physical therapy, the patient was discharged home on POD 6. At three months post-op, the patient was walking without a limp, had no proximal weakness, and

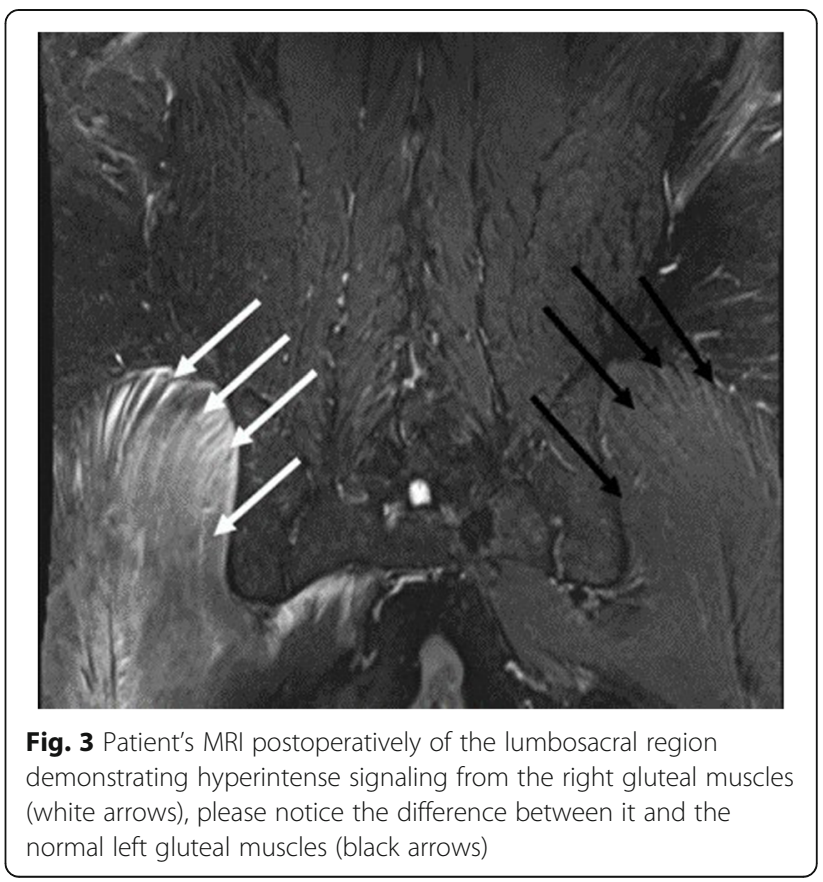


had no changes in his peripheral neurologic examination compared to his preoperative baseline.

\section{Discharge protocol}

Non-weight-bearing to left lower extremity and weightbearing as tolerated to the right lower extremity. Physical therapy was scheduled to improve muscle recovery and regain strength. The patient was given forms with information on diabetic foot care, pain medicine instructions, walker use, fall prevention, and home safety. Outpatient clinic visits were scheduled every two weeks to monitor the patient's recovery.

\section{Discussion}

Gluteal compartment syndrome is a rare condition that mainly occurs after trauma directly to the gluteal area or prolonged immobilization with pressure on the gluteal region after intoxication or prolonged surgery $[2-4,10$, 11]. Acute pelvic trauma can cause gluteal compartment syndrome due to local swelling from the injury that compromises vascular structures within a closed fascial space [1, 11, 12]. Postoperative gluteal compartment syndrome can occur due to local surgical trauma where structures have been incised and manipulated leading to edema; however, most cases of postoperative gluteal compartment syndrome affect the non-operative anatomical site due to prolonged immobilization and pressure.

A detailed literature review was performed to identify cases of positional gluteal compartment after orthopedic procedures. Cases due to direct trauma, vascular causes (e.g. injury to the gluteal vessels), intoxication, or those following non-orthopedic surgeries were excluded. We considered spinal procedures and extremity microsurgery among orthopedic surgeries. Cases of gluteal compartment syndrome following operative intervention on the ipsilateral hip (e.g. total hip arthroplasty) were considered "local trauma" and were excluded from this report. One article described bilateral gluteal compartment syndrome after total hip arthroplasty [13], we only included the contralateral side in the review as the ipsilateral side was considered local trauma. Thirteen case series/ case reports were included. Table 1 shows the details of the included papers/ cases. All studies were retrospective case reports [6, 10-17]. The average age was 53.2 years old, with most cases (84.6\%) being males and the average BMI was 33.7 (from the studies that recorded BMI). The average operation time was $3 \mathrm{~h}$.

Six patients were positioned supine during surgery; two of the cases used lithotomy position; three cases with lateral positioning during hip surgeries had gluteal compartment syndrome develop on the lower side that patient laid on. There were two cases after lumbar decompression surgeries. In these two cases, the patients were positioned in the knee-chest/elbow position with "buttock support". In our case, the procedure was performed in the supine position with elevation of the right side of the body with a "bump" under the right gluteal area to keep the left lower limb externally rotated. The use of a "bump" as well as the use of buttocks supports should be considered as a possible cause of gluteal compartment syndrome due to constant increased localized pressure.

Previous studies have found that major risk factors for gluteal compartment syndrome include obesity, prolonged operative time, and epidural anesthesia $[3,11$, 18]. Our patient had a morbidly obese BMI of 42 . This study's literature review had patients with an average BMI of 33.7 indicating moderate obesity. This seems to be a factor contributing to the development of gluteal compartment syndrome due to elevated pressure from the increased patient weights and from prolonged surgeries that are typically associated with more obese patients. These cases require a lower threshold for suspicion postoperatively.

Nine patients in our review had epidural anesthesia used for the operation and/or postoperatively. It has been mentioned in the literature that epidural analgesia may predispose susceptible patients to gluteal compartment syndrome $[12,17]$. In our case, the patient underwent the surgery under general anesthesia that why he had a severe pain shortly postoperative, this may support the use of general anesthesia in certain surgical interventions, which have the high risk of the position related compartment syndrome.

The most common clinical signs for gluteal compartment syndrome included pain in the gluteal region (92.3\%), non-compressible tense swelling of the buttocks area with possible erythema $(84.6 \%)$, pain that did not improve with analgesics (53.8\%), pain elicited with passive range of motion of the hip (38.5\%), and sensory/ motor nerve dysfunction with the sciatic nerve distribution (38.5\%). Four patients experienced foot drop $(30.8 \%)$. Out of the 13 cases, only one was diagnosed based on measuring compartmental pressures and the other 12 were based on clinical findings and patient symptoms. All the published cases were treated with a fasciotomy. In our case, the gluteal and back of the thigh pain was the first and the main symptom of our case which developed immediately postoperatively, in addition to tense gluteal region on the physical examination.

The symptoms and signs of gluteal compartment syndrome can be aided by labs and imaging to rule out other causes of the presenting symptoms. Creatine kinase and potassium levels are often elevated due to muscle ischemia [19]. Thus, given the large muscle mass involved, it is likely that a rise in CK may be one of the 


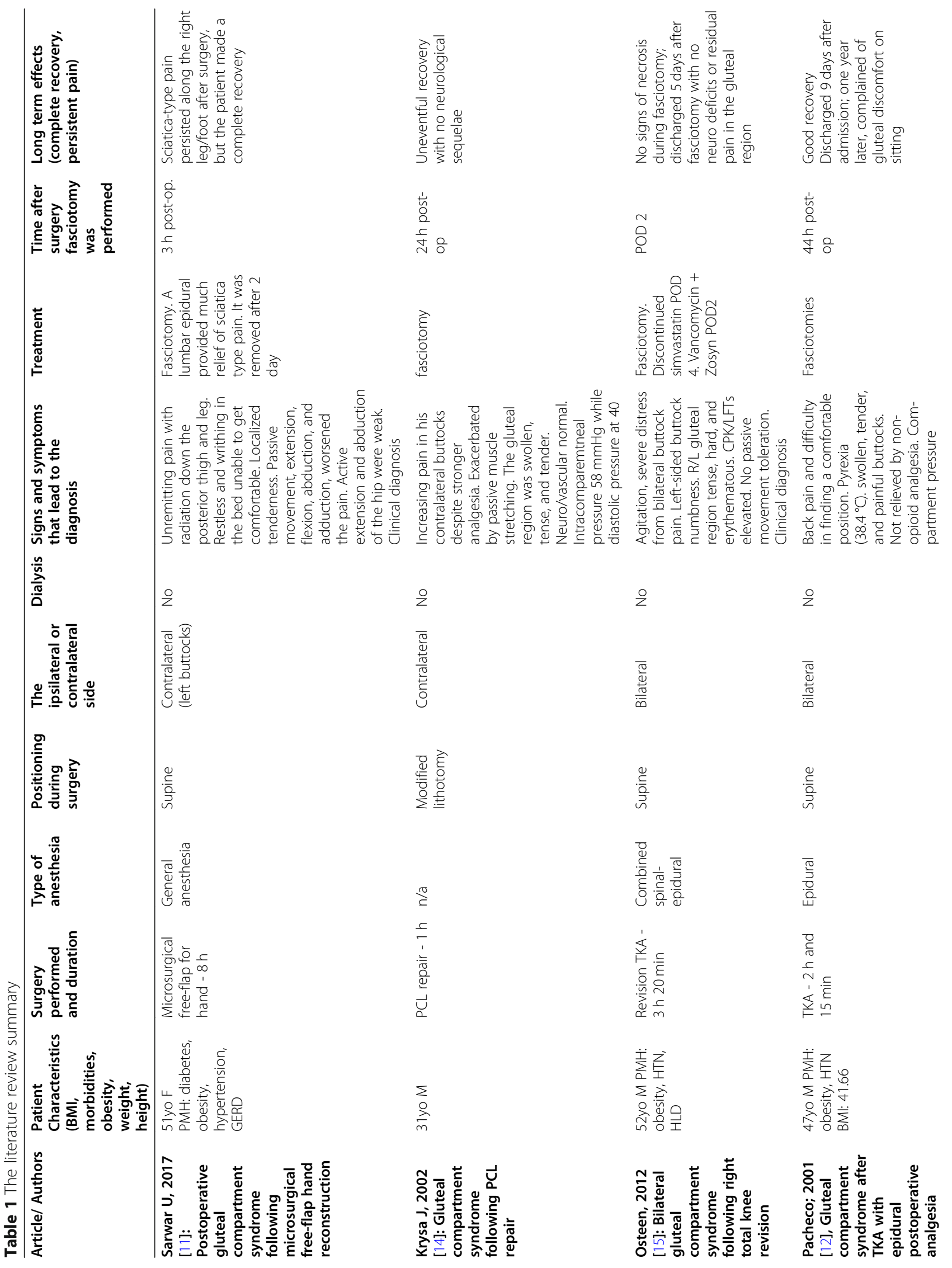




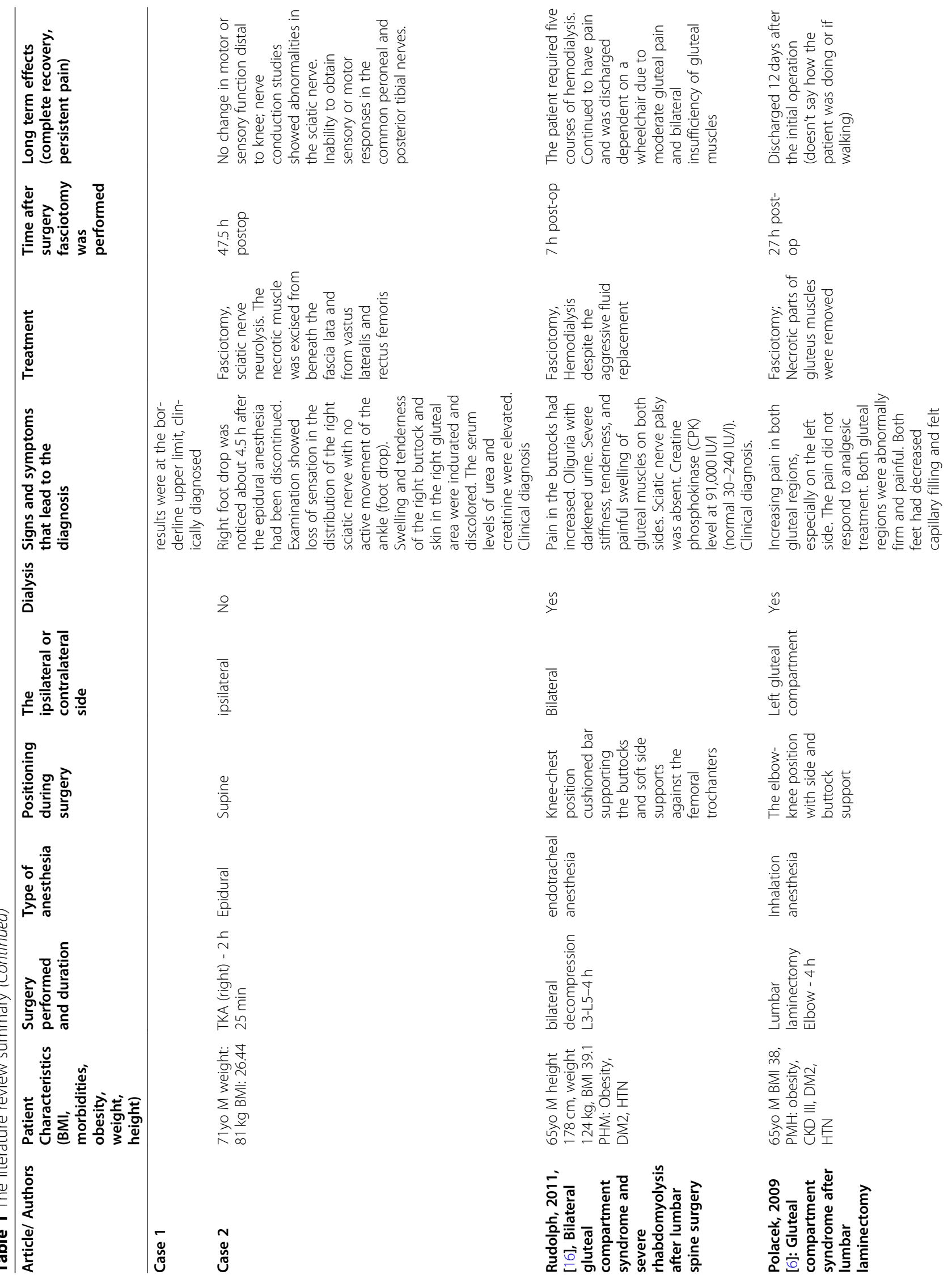




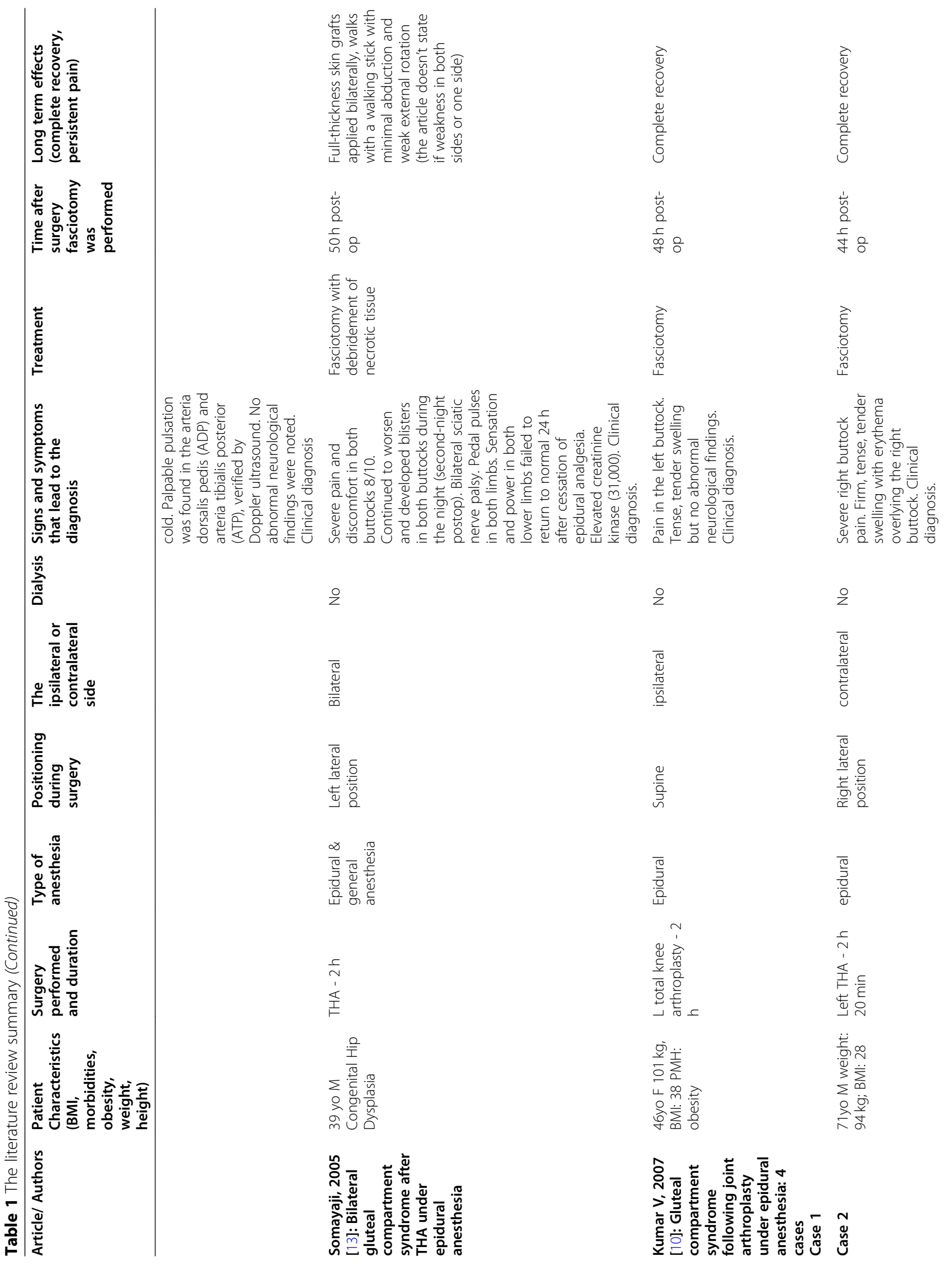




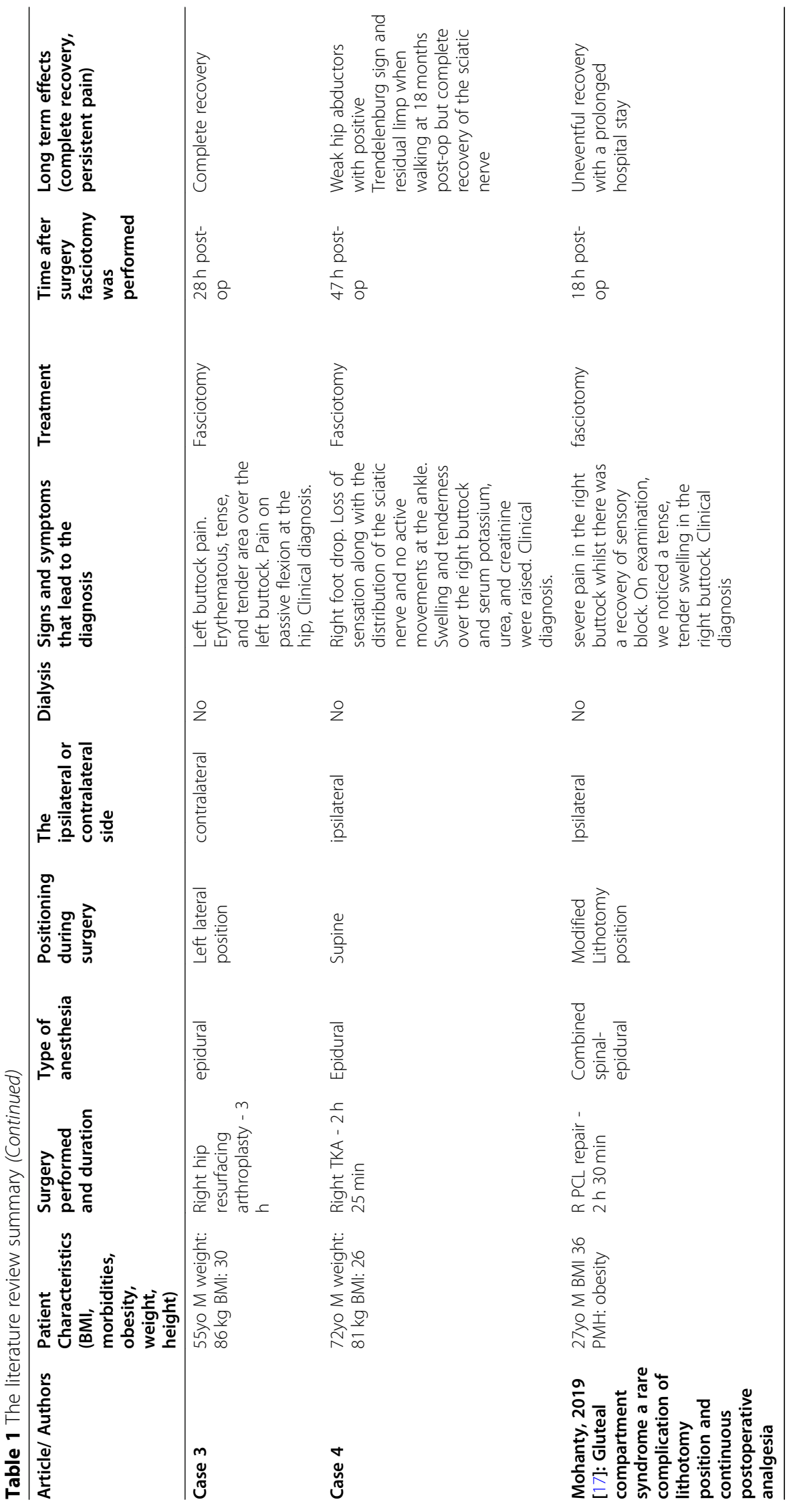


signs of compartment syndrome. In our patient, the creatine kinase level was not recorded until POD 2 and was markedly elevated (more than 49,000). This high value indicated that significant tissue damage had already occurred. Earlier measurements of CK could have supported the diagnosis of gluteal compartment syndrome. In the literature review, two cases out of the 13 (15.4\%) required dialysis due to renal affection by the circulating myoglobin from the muscle injury.

Our literature review revealed that the more time that elapses until fasciotomy, the worse outcome for the patient. All the published cases were treated with a fasciotomy. The average time after surgery to fasciotomy was $33.5 \mathrm{~h}$. The patients that did not achieve a complete recovery had fasciotomies performed a minimum of $44 \mathrm{~h}$ after surgery. Thus, the diagnosis of gluteal compartment syndrome must be made promptly to treat as soon as possible and to achieve a better likelihood of a complete recovery. In many cases, due to the rarity of the condition, the masking of the symptoms from epidural anesthesia or more relevant issues from the primary surgery, the diagnosis may be delayed.

In our case, the diagnosis of position gluteal compartment syndrome was missed for the first $36 \mathrm{~h}$ as the patient was assumed to have radicular symptoms due to possible lumbar spine etiology. Once the diagnosis was confirmed, due to existing literature expressing more complications with late fasciotomies and fear of operating on necrosed muscle which carries a high incidence of infection, it was decided that a fasciotomy would not be performed [20]. Fortunately, the patient completely recovered with no sequelae from the compartment syndrome. This article should not be interpreted, by any means, as a message that we encourage managing these cases nonoperatively. It is simply a description of the course of the disease in our patient. In our literature review, Eight of the patient (61.5\%) achieved a complete recovery while five patients (38.5\%) had persistent symptoms including gluteal discomfort with pressure $(2 / 13$, $15.4 \%)$, sciatic nerve sensory or motor dysfunction (1/13, 7.6\%), and gluteal muscles weakness with Trendelenburg sign $(3 / 13,23 \%)$ (One patient had 2 long term sequalae).

\section{Conclusion}

Gluteal compartment syndrome is a surgical emergency that must be considered postoperatively especially in obese patients with prolonged operation times who experience acute buttock pain. The use of positional bars or "bumps" in the gluteal area should be used with caution and raise awareness of this complication after orthopedic surgeries.

\section{Abbreviations}

MRI: Magnetic Resonance Imaging.: BMI: Body Mass Index; POD: PostOperative Day; CK: Creatine Kinase; BUN/Cr: Blood Urea Nitrogen/Creatinine

\section{Acknowledgements}

None.

\section{Authors' contributions}

RK: drafted manuscript, helped in data collection (articles of gluteal compartment syndrome assessment). MC: did most of the data collection (articles of gluteal compartment syndrome assessment) and analysis of the data and the Table. AW: did the description of the case and helped with the discussion. AT: planned the study design, reviewed the manuscript. AA: wrote the manuscript, reviewed the data of the table, finalized the submission and supervised all the other authors. All authors read and approved the manuscript.

\section{Funding}

No funding was obtained for this research.

This research did not receive any funds. We would like to ask for waiver/

discount for the APCs as there is no secured funds for the publications' fees.

Availability of data and materials

All materials (consent, pictures, labs) are available for review if needed.

\section{Ethics approval and consent to participate}

Written informed consent was obtained by the patient featured in this article for publication of the case report including accompanying images and protected health data. The consent is available for review by the editor-in-chief upon request.

Texas Tech University Health Science Centers of El Paso Institutional Board Review (IRB) consider all "case reports" as waived from obtaining approval so long consent was obtained from the patient.

Consent for publication

A consent to publish was obtained from the patient himself.

\section{Competing interests}

The authors declare that they have no competing interests.

\section{Author details}

${ }^{1}$ Department of Orthopedic Surgery, Paul L. Foster School of Medicine, Texas Tech University Health Sciences Center, El Paso, TX 79905, USA. ${ }^{2}$ Paul L. Foster School of Medicine, Texas Tech University Health Sciences Center, El Paso, TX 79905, USA. ${ }^{3}$ Department of Orthopedic Surgery, Maimonides Medical Center, Maimonides Bone and Joint Center, 6010 Bay Parkway, Brooklyn, NY 11204, USA.

Received: 29 April 2020 Accepted: 8 September 2020

Published online: 15 September 2020

\section{References}

1. Diaz Dilernia F, Zaidenberg EE, Gamsie S, Taype Zamboni DE, Carabelli GS, Barla JD, Sancineto CF. Gluteal compartment syndrome secondary to pelvic trauma. Case Rep Orthop. 2016;2016:2780295.

2. Hynes JE, Jackson A. Atraumatic gluteal compartment syndrome. Postgrad Med J. 1994;70(821):210-2.

3. lizuka S, Miura N, Fukushima T, Seki T, Sugimoto K, Inokuchi S. Gluteal compartment syndrome due to prolonged immobilization after alcohol intoxication: a case report. Tokai J Exp Clin Med. 2011;36(2):25-8.

4. Liu HL, Wong DS. Gluteal compartment syndrome after prolonged immobilisation. Asian J Surg. 2009;32(2):123-6.

5. Lawrence JE, Cundall-Curry DJ, Stohr KK. Delayed presentation of gluteal compartment syndrome: the argument for fasciotomy. Case Rep Orthop. 2016;2016:9127070.

6. Polacek M, Nymoen O, Johansen O. Gluteal compartment syndrome after lumbar laminectomy. BMJ Case Rep. 2009;2009:bcr0820092165.

7. Henson JT, Roberts CS, Giannoudis PV. Gluteal compartment syndrome. Acta Orthop Belg. 2009;75(2):147.

8. Targa L, Droghetti L, Caggese G, Zatelli R, Roccella P. Rhabdomyolysis and operating position. Anaesthesia. 1991;46(2):141-3.

9. Bostanjian D, Anthone GJ, Hamoui N, Crookes PF. Rhabdomyolysis of gluteal muscles leading to renal failure: a potentially fatal complication of surgery in the morbidly obese. Obes Surg. 2003;13(2):302-5. 
10. Kumar V, Saeed K, Panagopoulos A, Parker PJ. Gluteal compartment syndrome following joint arthroplasty under epidural anaesthesia: a report of 4 cases. J Orthop Surge. 2007;15(1):113-7.

11. Sarwar U, Ting J. Postoperative gluteal compartment syndrome following microsurgical free-flap hand reconstruction: the importance of early recognition and treatment. Case Rep. 2017;2017:bcr-2017.

12. Pacheco RJ, Buckley S, Oxborrow NJ, Weeber AC, Allerton K. Gluteal compartment syndrome after total knee arthroplasty with epidural postoperative analgesia. J Bone Joint Surg Br. 2001;83(5):739-40.

13. Somayaji HS, Hassan AN, Reddy K, Heatley FW. Bilateral gluteal compartment syndrome after total hip arthroplasty under epidural anesthesia. J Arthroplast. 2005;20(8):1081-3.

14. Krysa J, Lofthouse R, Kavanagh G. Gluteal compartment syndrome following posterior cruciate ligament repair. Injury. 2002;33(9):835-8.

15. Osteen KD, Haque SH. Bilateral gluteal compartment syndrome following right total knee revision: a case report. Ochsner J. 2012;12(2):141-4.

16. Rudolph T, Løkebø JE, Andreassen L. Bilateral gluteal compartment syndrome and severe rhabdomyolysis after lumbar spine surgery. Eur Spine J. 2011;20(2):180-2.

17. Mohanty CR, Sahoo AK, Panda R, Jain M. Gluteal compartment syndrome a rare complication of lithotomy position and continuous postoperative epidural analgesia. J Anaesthesiol Clin Pharmacol. 2019;35(3):403.

18. Ambar M, Kelley R. Gluteal compartment syndrome after robotic left adrenalectomy. Am Surg. 2014;80:101-2.

19. Cone J, Inaba K. Lower extremity compartment syndrome. Trauma Surg Acute Care Open. 2017;2(1):e000094.

20. Ebraheim NA, Abdelgawad AA, Ebraheim MA, Alla SR. Bedside fasciotomy under local anesthesia for acute compartment syndrome: a feasible and reliable procedure in selected cases. J Orthopaed Traumatol. 2012;13(3):153-7.

\section{Publisher's Note}

Springer Nature remains neutral with regard to jurisdictional claims in published maps and institutional affiliations.

Ready to submit your research? Choose BMC and benefit from:

- fast, convenient online submission

- thorough peer review by experienced researchers in your field

- rapid publication on acceptance

- support for research data, including large and complex data types

- gold Open Access which fosters wider collaboration and increased citations

- maximum visibility for your research: over $100 \mathrm{M}$ website views per year

At $\mathrm{BMC}$, research is always in progress.

Learn more biomedcentral.com/submissions 